\title{
Metabolism of the Antituberculosis Drug Ethionamide
}

\author{
Nuno Vale ${ }^{1, *}$, Paula Gomes ${ }^{1}$, and Hélder A. Santos ${ }^{2, *}$ \\ ${ }^{1}$ Centro de Investigação em Química da Universidade do Porto, Department of Chemistry and Biochemistry, Faculty of Sciences, \\ University of Porto, R. Campo Alegre, 687, P-4169-007 Porto, Portugal; ${ }^{2}$ Division of Pharmaceutical Technology, Faculty of Phar- \\ macy, University of Helsinki, P.O. Box 56 (Viikinkaari 5E), FI-00014 Finland
}

\begin{abstract}
Ethionamide (ETH) is an important second-line antituberculosis drug used for the treatment of patients infected with multidrug-resistant Mycobacterium. Although ETH is a structural analogue of isoniazid (INH), both are pro-drugs that need to be activated by mycobacterial enzymes to exert their antimicrobial activity. ETH mechanism of action is thought to be identical to INH although the pathway of activation is distinct from that of INH. ETH is activated by an EthA enzyme, leading to the formation of an Soxide metabolite that has considerably better activity than the parent drug. This review comprehensively examines the aspects related with the metabolism of ETH since its discovery up to today.
\end{abstract}

Keywords: Ethionamide, ETH-SO, EthA, EthR, ETH-NAD, metabolism, tuberculosis, mycobacterium tuberculosis, multidrug resistance.

\section{INTRODUCTION}

Tuberculosis is an infectious disease caused by the bacillus $M$. tuberculosis and is still a world health problem of staggering proportions. About one-third of the world's population is infected with M. tuberculosis without exhibiting symptoms of the disease. This airborne disease typically affects the lungs, but can also affect other sites of the body. Although only a relatively small proportion of people infected with $M$. tuberculosis will go on to develop tuberculosis disease, in the case of people infected with the human immunodeficiency virus (HIV) the probability of developing tuberculosis is rather high. Tuberculosis is generally thought to develop in an individual as a consequence of one of three processes: progression of primary infection, exogenous reinfection, or endogenous reactivation [1-3].

In 1993, the World Health Organization (WHO) declared tuberculosis a global public health emergency. According to the 2011 WHO report $[1,2]$, there were 8.8 million incident cases of tuberculosis in 2010, 1.1 million deaths from tuberculosis among HIVnegative people and an additional 0.35 million deaths from HIVassociated tuberculosis. In the same year, there were 5.7 million notifications of new and recurrent cases of tuberculosis. A large effort has been put forward in several countries to fight against this disease and the estimated investment for treatment in 97 countries with $92 \%$ of the world's tuberculosis is expected to be USD 4.4 billion in 2012 [1]. Tuberculosis is spread from person to person through the air. When a person with lung tuberculosis coughs, sneezes or spites, the tuberculosis germs propel into the air. A person needs to inhale only few of these germs to become infected [1].

The first line drugs normally employed to treat tuberculosis drug resistance are isoniazid (INH), ethambutol, pyrazinamide and rifampin [3]. When the infection is unresponsive to the treatment with first line drugs, second line drugs come into play. Because of the emergence of multidrug-resistant (MDR) strains of M. tuberculosis, second-line drugs such as ethionamide (ETH) have become increasingly important as replacements for INH and rifampicin, although ETH is relatively weak tuberculosis drug with usual

*Address correspondence to these authors at the Centro de Investigação em Química da Universidade do Porto, Department of Chemistry and Biochemistry, Faculty of Sciences, University of Porto, R. Campo Alegre, 687, P4169-007 Porto, Portugal; Tel: +351 2 20402567; Fax: +351 2 20402563; E-mail: nuno.vale@fc.up.pt

Tel: +358 9 19159160; Fax: +3589 19159144;

E-mail: helder.santos@helsinki.fi treatments that can last over 2 years with several side effects [4], as opposed to 6-9 months with INH and rifampin-containing regimens [5].

ETH is a prodrug that must undergo metabolic activation to exert its cytotoxic effects. ETH (1, Fig. (1)) was first used in the chemotherapy of tuberculosis in the early 1950's. The feature that distinguishes structurally and classifies this drug is the presence of a thioamide function. It was recognized that S-oxygenation of the thiourea moiety of ETH was involved in the bioactivation of a hepatotoxic metabolite [6], in a similar manner to what had been shown earlier for thiocarbamides [7]. This S-oxygenation also determines the therapeutic efficacy of ETH. Ten years later ETH propyl analogue, prothionamide, PTA (2, Fig. (1)), was introduced into clinical treatment because it was shown in vitro to be as active as ETH against M. tuberculosisin contrast to the experimental tuberculosis in the mouse, but appeared to be better tolerated by patients $[8,9]$.

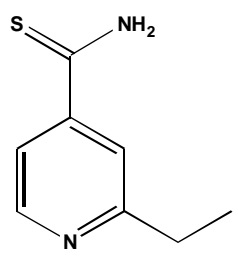

(1)

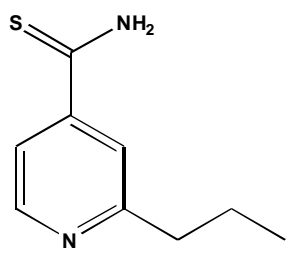

(2)<smiles>NNC(=O)c1ccncc1</smiles>

(3)
Fig. (1). Chemical structure of ETH (1), PTA (2) and INH (3). These prodrugs have similar structures but INH is activated by a catalase-peroxidase, whereas ETH and PTA are activated by a flavin-dependent monooxygenase (FMO).

These drugs have been used in the treatment of mycobacterial infections of $M$. leprae and $M$. avium $[10,11]$. They are the most frequently used drugs for the treatment of drug-resistant tuberculosis and, therefore, are becoming increasingly relevant as the number of MDR and extensively drug-resistant cases is increasing worldwide $[12,13]$. ETH and PTA are structurally similar to INH (3, Fig. (1)), which has been successful in the treatment of tuberculosis infection in the past. INH is an antibacterial drug that has been used to both prevent and treat tuberculosis since 1952. INH should be part of the treatment for all persons with tuberculosis unless there is a compelling reason to omit it, such as allergy to the pharmacologic agent. There are currently ten drugs with FDA approval for the 
treatment of tuberculosis and the first-line agents that form a fourdrug regimen for treatment of active tuberculosis are $\mathrm{INH}$, rifampin, ethambutol and pyrazinamide [14].

However, in recent history, poor compliance with the prolonged and complicated chemotherapeutic regimens currently used to treat tuberculosis, in conjugation with the advent of the AIDS epidemic and the increased mobility of human populations, has led to the emerging of numerous MDR M. tuberculosis strains $[15,16]$. Resistance to frontline therapeutics, such as INH, results in the treatment of patients with "second-line" agents that are less effective and/or more toxic [17]. One of the most effective in the treatment of tuberculosis is ETH.

For 25 years, the main research involving ETH was focused on the type of metabolites formed [18-28], starting, thus, the study of ETH metabolism. During this period the principal metabolite identified was ethionamide sulphoxide (4, Fig. (2)). In recent years, the studies involving the pharmacokinetics (PK) of ETH are more complete and accurate. As an example, a study of the absorption and elimination of ETH in twelve healthy, adult male volunteers after administration of oral tablets and rectal suppositories can be mentioned [29]. Treatments compared 250-mg ETH tablets and a placebo suppository to a $500 \mathrm{mg}$ ETH suppository and two placebo tablets, given 7 days apart. In this study, the area under serum concentration-time curve was used to determine the relative bioavailability of drug from preparations. The relative bioavailability after rectal administration was $57.3 \%$ of that after oral administration. The maximum concentration after rectal administration was $33 \%$ of that after oral administration.

Auclair et al. reported the effect of food, orange juice, or antiacids on the absorption of a single oral 500-mg dose of ETH in healthy volunteers, including the bioequivalence assessment, and determined the ETH population PK parameters [30]. The PK behaviour of ETH was not significantly modified by the different conditions studied. Mean ratios for area under curve (AUC) ranged from 0.91 to 0.96 for the orange juice, food, and antiacid treatments, indicating a minimal effect on the relative bioavailability. ETH can be administered with food if tolerance is an issue [30].

The PK parameters of ETH were also determined following oral doses. ETH PK parameters were independent of age, weight, height, gender, and creatinine clearance [31]. Tuberculosis patients appeared to have lower volumes of distribution $(3.22 \mathrm{~L} / \mathrm{Kg})$ and clearance values $(1.88 \mathrm{~L} / \mathrm{h} / \mathrm{Kg})$ compared to healthy volunteers (Table 1). Therefore, this resulted in lower AUC values $(3.95 \mathrm{mcg}$ $\mathrm{h} / \mathrm{mL}$ ) in the tuberculosis patients. ETH displayed a short elimination half-life (1.94 h).

In the second-line therapy for drug-resistant tuberculosis, ETH should be administered with other agents due to the rapid resistance development when the drug is used as monotherapy. The PK parameters of ETH are given in Table 1. PK parameters differed between healthy subjects and tuberculosis patients, resulting in a lower AUC for tuberculosis patients, possibly due to a decrease in bioavailability $[13,31]$.

Table 1. PK Parameters of ETH in Humans

\begin{tabular}{|c|c|c|c|c|}
\hline $\begin{array}{c}\text { Half- } \\
\text { life } \\
\text { (h) }\end{array}$ & $\begin{array}{c}\text { AUC } \\
(\mathbf{m g} . \mathbf{h} / \mathbf{L})\end{array}$ & $\begin{array}{c}\mathbf{C}_{\max } \\
(\boldsymbol{\mu} \mathbf{g} / \mathbf{m L} \mathbf{L})\end{array}$ & $\begin{array}{c}\text { Volume of } \\
\text { distribution } \\
(\mathbf{L} / \mathbf{K g})\end{array}$ & PK methodology \\
\hline \hline 1.94 & 7.67 & 2.16 & $\begin{array}{c}93.5 \\
\text { (sugar coated } \\
\text { tablets) }\end{array}$ & $\begin{array}{c}\text { Mean PK for 250 } \\
\text { mg oral dose using } \\
\text { film-coated tablets } \\
\text { in healthy adults } \\
\text { (FDA label) }\end{array}$ \\
\hline
\end{tabular}

FROM THE PRINCIPAL METABOLITE TO THE UNDERSTANDING OF ETH METABOLISM

\section{Activation of ETH}

The link between the ETH-resistant tuberculosis and mutations in the Rv3855 and Rv3854c genes clearly indicates that the oxidation of ETH-SO catalyzed by FAD-containing enzyme is critical for the activation of the drug to its cytotoxic metabolite $[32,33]$. This provided information on the catalytic and physical properties of this enzyme, and demonstrated that the catalyzes in the activation of ETH occurs in two steps rather than in one step. [17].

As a result of the oxidation of ETH by EtaA the S-oxide is formed (4, Fig. (2)) [17, 33], which is a metabolite that is known to retain the full antituberculosis activity of ETH [33]. Further oxidation of the S-oxide then produces the unstable sulfinic acid and, eventually, the 2-ethyl-4-carboxamidopyridine metabolite that has no antimycobacterial activity $[17,34]$. Therefore, the active metabolite of ETH lies between the S-oxide and 2-ethyl-4-carboxamidopyridine and might be the sulfinic acid or a product of its decomposition [35]. However, the sulfinic acid has not been isolated yet. The activation of ETH by the M. tuberculosis EtaA was also extended to other related compounds [36], such as thiacetoazone, PTA and isoxy (4,4'-diisoamyloxydiphenyl-thiourea) [37-39]. Magic angle spinning NMR studies in living mycobacterial cells on the EtaA-dependent oxidation of ETH have shown that the formation of the S-oxide and 4-pyridylmethanol metabolites are formed primarily outside the cells, and the accumulation of a unidentified activated intermediate formed inside the cells $[40,41]$.

\section{ETH Metabolites}

ETH, like INH, is thought to be a prodrug that must be converted to its active form by the bacterial cell. In vivo mammalian and bacterial studies suggested that the first metabolite of ETH is the thioamide S-oxide (ETH-SO, 4, Fig. (2)), which retains the biological activity of the parent drug $[17,33,42]$. Other metabolites identified in the whole cell bacterial systems include the ETH nitrile (5, Fig. (2)), ETH amide (6, Fig. (2)) and ETH alcohol (7, Fig. (2)) $[17,33]$.

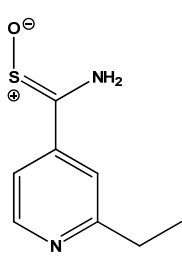

(4)

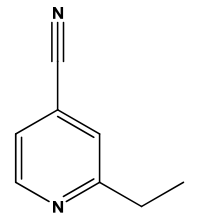

(5)

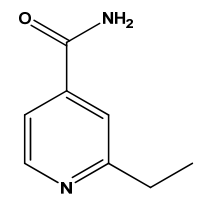

(6)

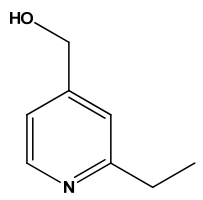

(7)
Fig. (2). Structures of metabolites of the ETH: (4), ETH S-oxide; (5), 2ethyl-4-cyanopyridine; (6), 2-ethyl-4-amidopyridine; and (7), 2-ethyl-4hydroxymetylpyridine.

De Barber et al. postulated that ETH is activated via the corresponding S-oxide (4) to a sulfinate that can form an analogous aldehyde equivalent (an imine) through a radical intermediate (see Fig. (3)). Hydrolysis of this imine could be followed by reduction of the resulting aldehyde to the metabolite alcohol, confirmed and identified as $\mathbf{7}$ by chromatography with a synthetic characterized alcohol standard [33].

A wide variety of toxic thiocarbonyl-containing compounds have been shown to be converted to the corresponding S-oxides during in vivo metabolism by mammals supporting this intermediate oxidation in the metabolic activation of ETH [43]. 


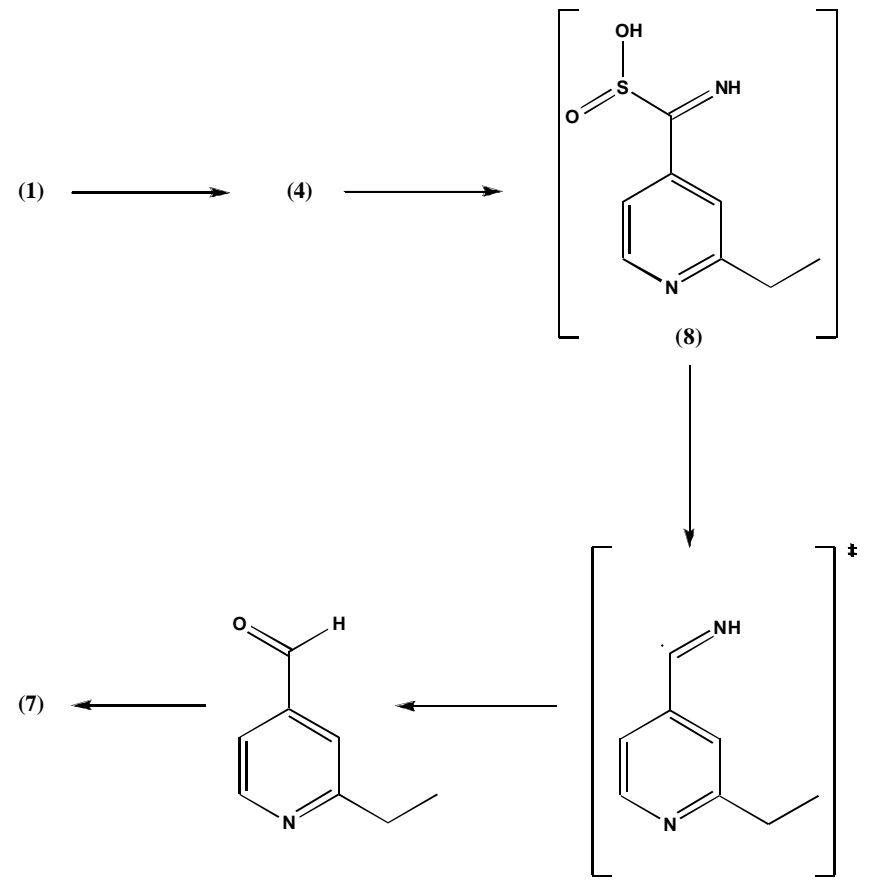

Fig. (3). Proposed activation process for the thioamide oxidation of ETH [33]. In vivo production of (2-ethyl-pyridin-4-yl) methanol (7) from ETH by whole cells of $M$. tuberculosis.

ETH-SO is not very reactive and, thus, it can be stored and physically characterized. The properties of ETH-SO, along with the observation that it is as lethal to the tuberculosis bacilli as ETH, suggested that ETH-SO itself requires further activation to a final cytotoxic species [32]. Incubation of authentic ETH-SO with ETH under turnover conditions shows, indeed, that it is further metabolized by the enzyme to another metabolite [9]. Chromatographic data of this second metabolite with synthesized standards identified it as 2-ethyl-4-amidopyrydine (6, Fig. (2)). This second metabolite is thus a product of the enzymatic action of ETH on ETH-SO $(\mathbf{1} \rightarrow \mathbf{4})$ and not a branching product stemming from an alternative reaction with ETH [17]. However, 6 is likely not the actual enzymatic product of ETH and ETH-SO but rather is a more stable molecule resulting from the decomposition of this putative cytotoxic metabolite, possibly a sulfinic acid specie (8, Fig. (4)).
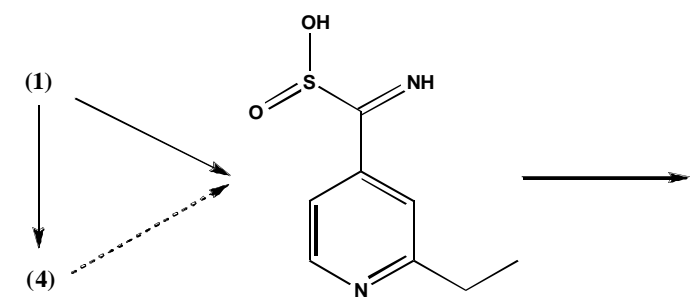

(8)

Fig. (4). Possible formation of ETH amide (6) via a sulfinic acid (8). The ETH amide has no antitubercular activity.

Cell incubations of $M$. tuberculosis with radiolabelled ETH have indicated that ETH-SO and ETH nitrile (5) are initially formed and accumulated to a maximum concentration over a couple of hours [33]. Following this early concentration increase, ETH-SO and 5 concentrations begin to decrease, and an increase in the ETH amide (6) and ETH alcohol (7) amounts are observed [33].

\section{ETH Metabolism}

To understand the ETH metabolism it is essential to cite the work of Johnsson et al., who suggested that this drug could be metabolized to a higher S-oxide capable of undergoing addition reactions to the nucleophilic protein side chain [44]. The experiments suggested for the first time a molecular mechanism of action, where ETH was activated by unidentified mycobacterial enzymes [44]. After that, two works were reported and explained the ETH activation $[32,33]$. Firstly, it was demonstrated that overproduction of Rv3855 (EthR), a putative regulatory protein from $M$. tuberculosis, confers ETH resistance whereas overproduction of an adjacent, clustered monooxygenase (Rv3855c, EthA) confers ETH hypersensitivity [33]. The production of EthA appears to be negatively regulated by EthR and correlates directly with $\left[{ }^{14} \mathrm{C}\right]-\mathrm{ETH}$ metabolism, suggesting that EthA is the activating enzyme responsible for thioamide oxidation and subsequent toxicity [33].

In another work, it was reported the identification of an activator for ETH. The ETH activator Rv3854c (EthA) was found to be homologous to various monooxygenases and induced ETH sensitivity when overexpressed in mycobacteria [32]. Also, the neighbouring open reading frame ( $\mathrm{Rv} 3855)$, which was found homologous to transcriptional repressors of the TetR family, led to ETH resistance when overexpressed. In addition, chromosomal inactivation of this gene by transposition led to ETH hypersensitivity. These data suggested that Rv3855 (EthR), regulates the production of EthA, which subsequently activates the pro-drug ETH [32].

After the identification of the ability of EthA-enzyme to activate the drug, it was reported that mutations within EtaA structural genes were associated with relatively high levels of ETH resistance, i.e. approximately $76 \%$ of isolates resistant to $>50 \mu \mathrm{g} / \mathrm{mL}$ of ETH had such mutations [45].

Vannelli et al. reported that the enzyme EthA (Rv3854c code) is a flavoprotein containing a single FAD group that catalyzes the $\mathrm{NADPH}$ - and $\mathrm{O}_{2}$-dependent monooxygenation of ETH to the corresponding S-oxide (4) [17]. The S-oxide which has a similar biological activity as ETH, is further oxidized by EthA to 2-ethyl-4amidopyridine (6). This flavoenzyme also oxidizes thiacetazone, thiobenzamide, and isothionicotinamide, and thus, is probably responsible, as suggested by the observation of crossover resistance, for the oxidative activation of other thioamide antituberculosis drugs [17]. It was discovered that purified EthA displayed a remarkably low activity with ETH.

Typical components of the mycobacterial cell wall are mycolic acids. It has been shown that the ability of mycobacteria to synthesize the so-called wax ester micolic acids relies on a BaeyerVilliger oxidation step. Hinted by the presence of a Baeyer-Villiger monooxygenase sequence motif in the EthA sequence, it was discovered that the enzyme converts a wide range of ketones to the corresponding esters or lactones via a Baeyer-Villiger reaction, indicating that EthA represents a Baeyer-Villiger monooxygenase [42]. EthA is also able to catalyze enantioselective sulfoxidation of methyl-p-tolylsulfide [42]. Redox monitoring of the flavin cofactor during turnover of phenylacetone indicates that a step in the reductive half-reaction is limiting the rate of catalysis.

Vilchève et al. proposed the first mechanism of action of ETH, that is a drug activated by the monooxygenase EthA. The activated forms react with nicotinamide adenine dinucleotide $\left(\mathrm{NAD}^{+}\right)$to form an ETH-NAD adduct (Fig. (5)) [46]. This adduct inhibited the common target InhA, the NAD-dependent enoyl-ACP reductase of the fatty acid synthase type II system, resulting in the inhibition of mycolic acid biosynthesis and cell lysis. The resistance to ETH is associated with recessive mutations in the genes encoding the activator of the drug, EthA, which prevents drug activation. ETH resistance is associated with dominant mutations in the gene encoding the common target of the drug, InhA, which result in target amplification or target modification [46]. 


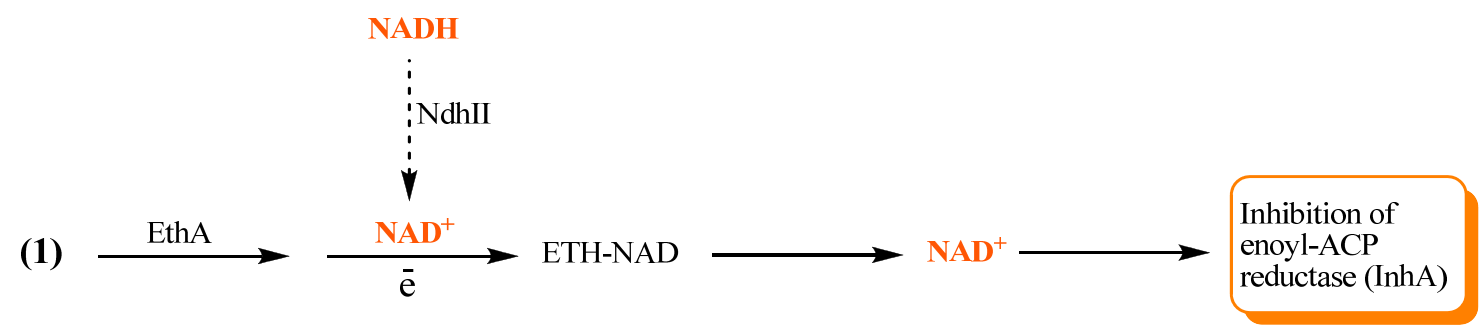

Fig. (5). Mechanism of action of ETH [46].

Hanoulle et al. showed that the intracellular metabolization of ETH strictly depends on the presence of the monooxygenase (EthA) and that EthA-dependent activation of ETH is coupled to a precise molecular sorting mechanism of the ETH metabolites [40]. The authors reported that substantial amounts of the ETH-treated mycobacteria produced the previously identified ETH metabolite 2-ethyl4-hydroxymethylpyridine (7, Fig. (2)), which is present exclusively outside of the bacteria.

The appearance of new data about the type of metabolite formed can be clarified by other research works involving the metabolism of thioamides $[47,48]$. Thioamide could be metabolized to support bacterial growth but the mechanism of nitrogen release was not established [47]. In another study, a bacterium was isolated for its ability to grow on thioacetamide as its role nitrogen source. A pure culture was obtained, determined to be a Ralstonia pickettii strain, and its mechanism of thioacetamide and thiobenzamide metabolism were elucidated. It was proposed that $R$. pickettii degrades thioamides via a mechanism involving consecutive oxygenations of the thioamide sulphur atom [33]. Using a cell-based activation method, it was demonstrated that thioamides (as ETH) formed covalent adducts with NAD and that these adducts were tightly binding inhibitors of $M$. tuberculosis and M. leprae IhnA [34]. The crystal structures of the inhibited M. leprae and M. tuberculosis InhA complexes provided the molecular details of target-drug interactions. ETH-NAD showed monomolar inhibitor concentration $\left(\mathrm{K}_{\mathrm{i}}\right)$ against $M$. tuberculosis InhA. Nishida et al. further determined the $\mathrm{IC}_{50}$ values from the dose-response plots of enzyme fractional activity as a function of the $\mathrm{K}_{\mathrm{i}}$ values [35].

In Fig. (6) two plausible mechanisms are represented for the activation of ETH. Both routes will lead to the observed ETH-NAD adduct, retaining a tetrahedral carbon at position 4 of the nicotinamide ring [37].

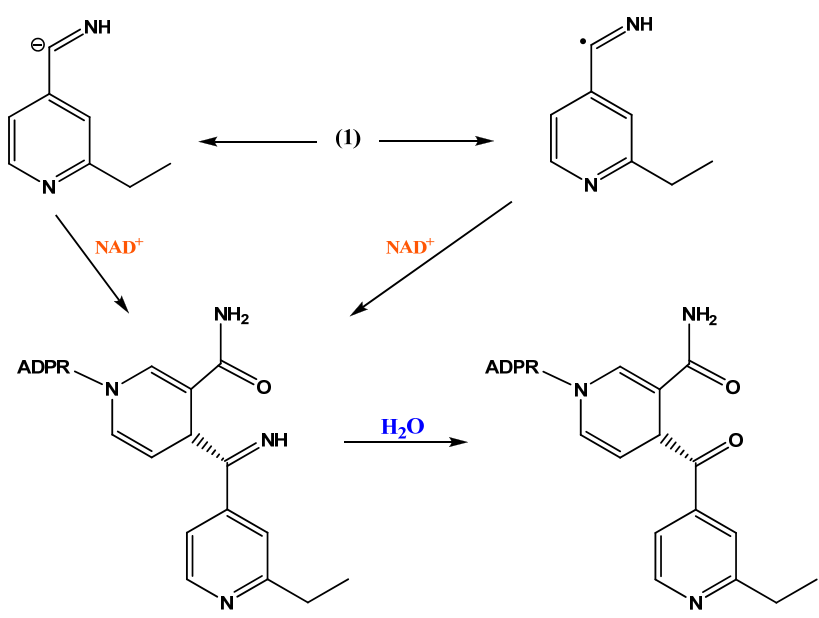

Fig. (6). Possible reaction mechanisms for the activation of ETH and the formation of ETH-NAD [37].
Dover et al. reported that EthA, a common activator of thiocarbamide-containing drugs, acts on different mycobacterial targets [38]. This study indicated that EthA is the activator of three antituberculosis drugs: ETH, thiacetazone (8, TAC, Fig. (7)) and isoxyl (9, ISO, Fig. (7)).<smiles>CC(=O)Nc1ccc(/C=N/NC(N)=S)cc1</smiles>

(8)

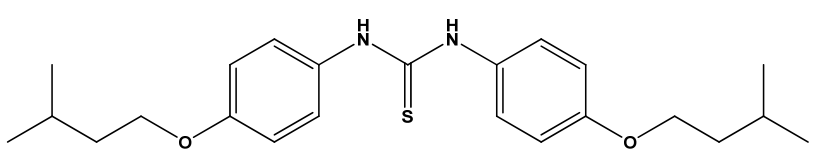

(9)

Fig. (7). Structures of the thiocarbamide-containing antituberculosis drugs: $\mathbf{8}$, thiacetazone (TAC); and $\mathbf{9}$, isoxyl (ISO).

Once activated, ETH inhibits mycolic acid biosynthesis by targeting InhA, which is also the primary target of activated INH (3, Fig. (1)). These aspects are represented in detail in Fig. (8) [38].

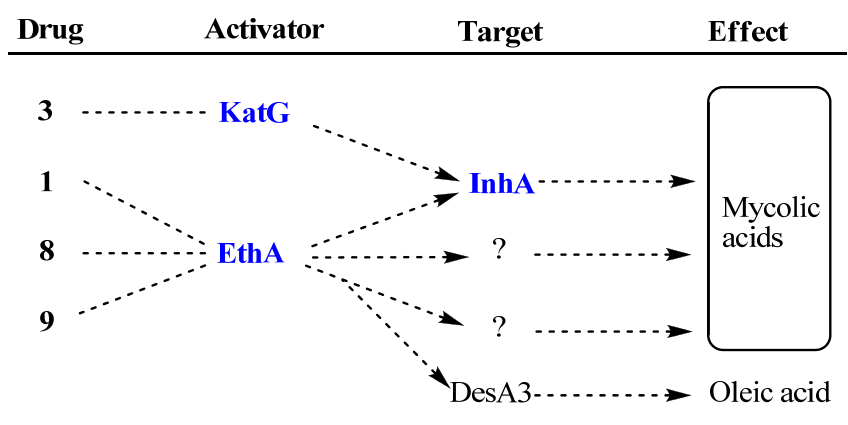

Fig. (8). Summary of the activation mechanism of the four antituberculosis drugs. Prodrugs get into tubercle bacilli by passive diffusion, where they are activated by specific proteins to a range of reactive radicals or species [38]. DesA3 (Rv3229c) from M. tuberculosis is a membrane-bound stearoyl coenzyme A $\Delta^{9}$ desaturase that reacts with the oxidoreductase Rv3230c to produce oleic acid.

Mycothiol (MSH) is the glutathione analogue for mycobacteria. Mutations in MSH biosynthetic genes have been associated with resistance to INH and ETH in mycobacteria. The construction of independent null deletion mutants for all four genes involved in the MSH biosynthesis pathway (MshA, MshB, MshC and MshD) showed different resistance to INH and ETH $[49,50]$.

One of the most pronounced characteristics observed in the first MSH mutant isolated from Streptomyces strains was its $>25$-fold increase in resistance to INH (3) [51]. The MshB-deficient mutant, 
which makes 5 to $10 \%$ of normal MSH levels, has been reported to be only slightly more resistant to INH than the wild type in a disk assay $[52,53]$, suggesting that moderate levels of MSH are sufficient to confer normal sensitivity to 3 . Also, enhanced resistance to ETH is another characteristic of the MshA-, MshB-, and MshDdeficient mutants, with complete resistance at $50 \mu \mathrm{g} / \mathrm{mL}[52,53]$. The high levels of resistance of the MSH mutants to 3 and ETH suggest that MSH is involved in the activation of these drugs, because both 3 and ETH are prodrugs which need to be activated intracellularly and whose reactive groups must be unmasked before inhibiting their target [54]. Recently, it was demonstrated that mutations in MSH biosynthesis genes may contribute to INH or ETH resistance across mycobacterial species, because these mutants showed low-level resistance to INH but were highly resistant to ETH [55]. The MshA, MshC, and MshB single deletion mutants were resistant to ETH, indicating that ETH resistance is modulate by the level of Msh in M. smegmatis. Surprisingly, the MsdD deletion mutant lacked Msh production but was sensitive to both INH and ETH [56].

It is important to note that in the second-line therapy for drugresistant tuberculosis, ETH should be administered with other drugs to avoid rapid development of resistance when the drug is used as monotherapy. The use of ETH and PTA (2, Fig. (1)) is increasing in MDR resistant strains $M$. tuberculosis. ETH is used interchangeably with 2 [57].

With the integration of EthR, which controls the resistance of $M$. tuberculosis to ETH, into a synthetic mammalian gene network, Weber et al. have been able to identify the licensed food additive 2phenylethyl-butyrate as a potent inhibitor of EthR in M. tuberculosis, which dramatically increases the sensitivity of this pathogen to the last-line-of-defense drug ETH and potentially to other EthAdependent compounds [58]. More recently, drug-like inhibitors of EthR were identified to boost the bioactivation of ETH [59]. These compounds were screened for their capacity to inhibit EthR-DNA interaction by cocrystallization with EthR. One of these analogs enabled the prepartion of a substantially reduced dose of ETH in order to lessen the capacity of mycobacterial load in an efficient manner as the conventional higher-dose used in the treatment [59]. Again, it was concluded that thiocarbamide-containing drugs, as ETH, were activated by the mycobacterial monooxygenase EthA, and the production of which was controlled by the transcriptional repressor EthR.

The mammalian FMOs (EC 1.14.13.8), a superfamily of flavoprotein monooxygenases active towards a wide range of xenobiotics, catalyse the oxidative metabolism of bioactive thiourea-based drugs [36, 60-63], and FMO1 and FMO3 have been shown in vitro to catalyse the oxygenation of thiacetazone (8, TAC, Fig. (8)), forming the same products as EtaA [62]. TAC and ETH act against mycobacteria in the lung, and were investigated for the ability of human FMO2.1 to catalyse the oxygenation of these antituberculosis drugs [34]. This protein catalyzes oxygenation of both TAC and $\mathrm{ETH}$, forming the same metabolites as those produced by human FMO1 and FMO3, and by the mycobacterial enzyme EthA. These results provide a potential explanation for some of the observed inter-individual differences in the efficacy and response to TAC and ETH, and have implications for the treatment of tuberculosis in subSaharan Africa and in individuals of recent African descent [34].

By studying the mutations of enzymes associated to ETH metabolism we can understand the resistance of the drug. Various mechanisms involved in mycothiol biosynsthesis were reported, including mutations altering EthA/EthR, InhA and its promoter, the NADH dehydrogenase encoded by $n d h$, and the MshA enzyme. However, the mechanism of resistance to ETH remained unknown for $19 \%$ of the $\mathrm{ETH}^{\mathrm{r}}$ (clinical isolates: $47 \mathrm{ETH}$-resistant), highlighting the complexity of the mechanisms of ETH resistance in $M$. tuberculosis [64].
Carette et al. demonstrated that the inhibitory effect of highly diverse specific ligands of EthR can be mimicked by the mutation G106W [65]. This explains how two small cyclic molecules, such as dioxane [66], induced the same conformational state as the one induced with hexadecyl-octanoate $[67,68]$. These results suggested that exploitation of deeper positions of this ligand pocket to increase their affinity/specificity would be successful as long as these molecules interact with the upper region of the surrounding glycine 106 [65]. Engohang-Ndong et al. reported that EthR, which encodes a repressor belonging to the TetR/CamR family of transcriptional regulators, negatively regulates the expression of EthA [69]. At this point, it is possible to propose the cycle for metabolism of ETH (Fig. (9)), according to its active form (ETH-SO), its activator (EthA) and the repressor implicated in drug resistance in mycobacteria $(\mathrm{EthR})$.

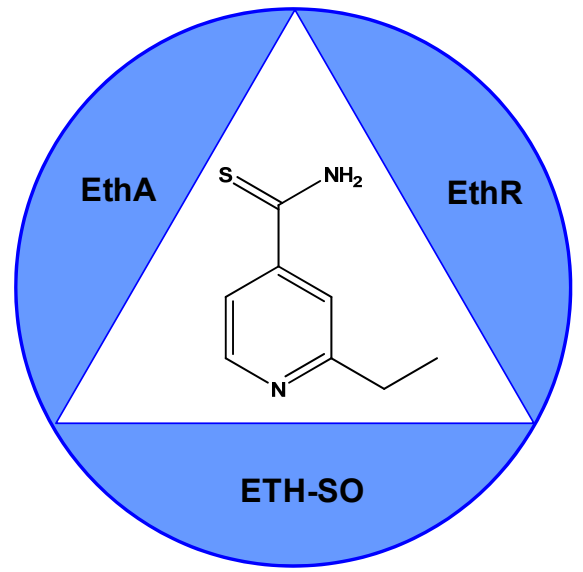

Fig. (9). The ETH cycle proposed.

A biophysical study of ETH was presented recently involving ETH. The interaction between ETH and serum albumin was investigated employing different spectroscopic techniques [70]. The results revealed that the secondary structure of the protein was affected upon interaction with the drug. The fluorescence results indicated the presence of static quenching mechanism in the binding of ETH to the protein. Based on spectral data it was concluded that the ETH bound to side I of the protein, which is located in the hydrophobic pocket of subdomain IIA [70].

After ionization, compounds with functional thioamide group exist under tautomeric equilibria [71] and, despite of that, it has been possible to develop new ETH derivatives, denominated by oxazolinyl (10, Fig (10)) and N-hydroxy-alkyl (11, Fig. (10)) [72]. This is an important step to fight the MDR-tuberculosis and the valuable contribution of new derivatives of ETH can help to understand better the metabolism of the parental drug. Other advantages can be the association of ETH with other drugs, such as gatifloxacin, which in combination with ETH has great promise for the treatment of tuberculosis [73].

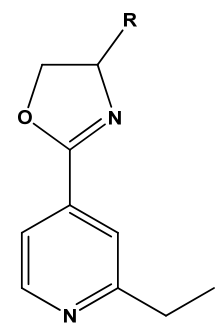

(10)

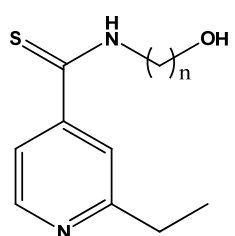

(11)
Fig. (10). New ETH derivatives: 10, $\mathrm{R}=\mathrm{H}$ or $\mathrm{CH}_{3}$; and 11, $\mathrm{n}=3-5$. 


\section{Site of Activation}

The ultimate site of action of ETH is the same as the one of INH. Gene array studies have shown that both ETH and INH induce similar patterns of protein expression [74], and mutations in the InhA gene give rise to resistance to both ETH and INH $[45,75]$. In addition, it has also been shown that both activated ETH and PTA inhibit EtaA [37], and that the basis for the inhibition of InhA by ETH and PTA yields ETA-NADH and PTA-NADH adducts, respectively, which are similar to the adduct obtained with INH [37]. The formation mechanism of the activated ETH molecule is possible due to the formation of the S-oxide preceded by hydrolysis of the putative sulfinic acid to give the amide [35]. This is explained by the fact that sulfinic acid is a good leaving group and can be displaced by nucleophiles, whereas $\mathrm{NAD}^{+}$is an electron deficient ring and is highly unlikely to act as a nucleophile. Therefore, the sulfinic acid might undergo homolytic cleavage to give the carbon radical, as addition to the $\mathrm{NAD}^{+}$ring followed by hydrolysis of the imine function [35]. Recently, by using high throughput microarray data and interactome network, Chen et al. have shown that the active drug-treated networks are associated with the trigger of fatty acid metabolism and synthesis, as well as to NADH-related processes, and that the efflux pumps processes appear to be the major mechanisms of resistance [76].

\section{CONCLUSION}

Global tuberculosis epidemic has been complicated by the recent worldwide emergence of MDR strains of M. tuberculosis. Recent attempts to potentiate the existing antimycobacterial activities, such as ETH and other drugs, have increased the possibility for targeting resistance which might offer a shortcut to broaden the chemotherapeutic options for tuberculosis treatment, thus decelerating the dissemination of drug resistant forms. ETH plays a central role in the treatment of patients that exhibit resistance to the frontline drugs. This anti-tuberculosis drug is known to strongly inhibit mycolic acid synthesis in $M$. tuberculosis. As a result of the second oxidative cycle, the oxidation of thioamide groups in ETH produces sulfoxides which are converted to sulfinic acid. The sulfinic acids can decompose and in some cases react with $\mathrm{NAD}^{+}$to generate adducts that reversibly inhibit cell wall synthesis in M. tuberculosis. In addition, it may serve as electrophilic agent that modifies proteins in either the mycobacterium or in the host tissue if produced by host FMO enzymes. This makes ETH a molecule of great interest still to fight against $M$ tuberculosis, which can even be further explored in the future by combining it with other therapeutic approaches.

\section{CONFLICT OF INTEREST} interest.

The authors confirm that this article content has no conflicts of

\section{ACKNOWLEDGEMENTS}

H.A. Santos acknowledges financial support from the Academy of Finland (decision numbers 252215 and 256394). N. Vale thanks Portuguese Foundation for Science and Technology (FCT) for financial support through Post-Doc grant SFRH/BPD/48345/2008.

\section{REFERENCES}

[1] Global tuberculosis control: WHO report, 2011, Geneva, Switzerland. http://www.who.int/tb/publications/global_report/en/ (Accessed February 23, 2012).

[2] Falzon, D.; Jaramillo, E.; Schunemann, H. J.; Arentz, M.; Bauer, M.; Bayona, J.; Blanc, L.; Caminero, J. A.; Daley, C. L.; Duncombe, C.; Fitzpatrick, C.; Gebhard, A.; Getahun, H.; Henkens, M.; Holtz, T. H.; Keravec, J.; Keshavjee, S.; Khan, A. J.; Kulier, R.; Leimane, V.; Lienhardt, C.; Lu, C.; Mariandyshev, A.; Migliori, G. B.; Mirzayev, F.; Mitnick, C. D.; Nunn, P.; Nwagboniwe, G.; Oxlade, O.; Palmero, D.; Pavlinac, P.; Quelapio, M. I.; Raviglione, M. C.; Rich, M. L.; Royce, S.; Rusch-Gerdes, S.;
Salakaia, A.; Sarin, R.; Sculier, D.; Varaine, F.; Vitoria, M.; Walson, J. L.; Wares, F.; Weyer, K.; White, R. A.; Zignol, M. WHO guidelines for the programmatic management of drugresistant tuberculosis: 2011 update. Eur. Respir. J., 2011, 38, 516528.

[3] Sahbazian, B.; Weis, S. E. Treatment of active tuberculosis: challenges and prospects. Clin. Chest. Med., 2005, 26, 273-282.

[4] Arbex, M. A.; Varella Mde, C.; Siqueira, H. R.; Mello, F. A. Antituberculosis drugs: drug interactions, adverse effects, and use in special situations. Part 2: second line drugs. J. Bras. Pneumol., 2010, 36, 641-656.

[5] Peloquin, C. A. Therapeutic drug monitoring in the treatment of tuberculosis. Drugs, 2002, 62, 2169-2183.

[6] Ruse, M. J.; Waring, R. H. The effect of methimazole on thioamide bioactivation and toxicity. Toxicol. Lett., 1991, 58, 37-41.

[7] Krieter, P. A.; Ziegler, D. M.; Hill, K. E; Burk, R. F. Increased biliary GSSG efflux from rat livers perfused with thiocarbamide substrates for the flavin-containing monooxygenase. Mol. Pharmacol., 1984, 26, 122-127.

[8] Rist, N. The antitubercular activity of ethioniamide (alphaethylthioisonicotinamide or Th 1314). An experimental and clinical study. Bibl. Tuberc., 1960, 15, 69-126.

[9] Fox, W.; Robinson, D. K.; Tall, R.; Kent, P. W.; Macfadyen, D. M A study of acute intolerance to ethionamide, including a comparison with prothionamide, and of the influence of a vitamin B-complex additive in prophylaxis. Tubercle, 1969, 50, 125-143.

[10] Fajardo, T. T.; Guinto, R. S.; Cellona, R. V.; Abalos, R. M.; Dela Cruz, E. C.; Gelber, R. H. A clinical trial of ethionamide and prothionamide for treatment of lepromatous leprosy. Am. J. Trop. Med. Hyg., 2006, 74, 457-461.

[11] Yajko, D. M.; Nassos, P. S.; Hadley, W. K. Therapeutic implications of inhibition versus killing of Mycobacterium avium complex by antimicrobial agents. Antimicrob. Agents Chemother., 1987, 31, 117-120.

[12] Centers for disease control and prevention. Emergence of Mycobacterium tuberculosis with extensive resistance to secondeline drugs - worldwide, 2000-2004. Morb. Mortal. Wkly. Rep., 2006, 55, 301-305.

[13] Crofton, J.; Chaulet, P.; Maher, D.; Grosset, J.; Harris, W.; Norman, H.; Iseman, M.; Watt, B. Guidelines for the management of multidrug-resistant tuberculosis. World Health Organization: Geneva. Switzerland, 1997.

[14] In American Thoracic Society, CDC, and Infections Diseases Society of America. Treatment of tuberculosis, MMWR, 2003; Vol. 52 (RR-11), pp. 1-60.

[15] Bass, J. B., Jr.; Farer, L. S.; Hopewell, P. C.; O'Brien, R.; Jacobs, R. F.; Ruben, F.; Snider, D. E., Jr.; Thornton, G. Treatment of tuberculosis and tuberculosis infection in adults and children. American Thoracic Society and The Centers for Disease Control and Prevention. Am. J. Respir. Crit. Care Med., 1994, 149, 13591374

[16] Pablos-Mendez, A.; Raviglione, M. C.; Laszlo, A.; Binkin, N.; Rieder, H. L.; Bustreo, F.; Cohn, D. L.; Lambregts-van Weezenbeek, C. S.; Kim, S. J.; Chaulet, P.; Nunn, P. Global surveillance for antituberculosis-drug resistance, 1994-1997. World Health Organization-International Union against tuberculosis and lung disease working group on anti-tuberculosis drug resistance surveillance. N. Engl. J. Med., 1998, 338, 1641-1649.

[17] Vannelli, T. A.; Dykman, A.; de Montellano, P. R. O. The antituberculosis drug ethionamide is activated by a flavoprotein monooxygenase. J. Biol. Chem., 2002, 277, 12824-12829.

[18] Acred, P.; Brown, D. M. The antitubercular properties of a series of thiols and sulphides. Br. J. Pharmacol. Chemother., 1960, 15, 485495.

[19] Kane, P. O. Identification of a metabolite of the antituberculous drug ethionamide. Nature, 1962, 195, 495-496.

[20] Weinstein, H. J.; Hallett, W. Y.; Sarauw, A. S. The absorption and toxicity of ethionamide. Am. Rev. Respir. Dis., 1962, 86, 576-578.

[21] Bieder, A.; Brunel, P.; Mazeau, L. Identification of 3 new metabolites of ethionamide: chromatography, spectrophotometry, polarography. Ann. Pharm. Fr., 1966, 24, 493-500.

[22] Johnston, J. P.; Kane, P. O.; Kibby, M. R. The metabolism of ethionamide and its sulphoxide. J. Pharm. Pharmacol., 1967, 19, 19 . 
[23] Pütter, J. Determination of prothionamide and ethionamide and their sulfoxides in blood-plasma. Arzneimittel-Forschung, 1972, 22, 1027-1031.

[24] Bialik, I. B.; Kalabukha, A. V. Concentration of ethionamide and prothionamide in the blood of patients with pulmonary tuberculosis. Vrach. Delo., 1973, 11, 97-100.

[25] Prema, K.; Gopinathan, K. P. Metabolism of ethionamide, a second-line antitubercular drug. J. Indian Inst. Sci., 1976, 58, 245251.

[26] Jenner, P. J.; Ellard, G. A. High-performance liquid chromatographic determination of ethionamide and prothionamide in body fluids. J. Chromatogr., 1981, 225, 245-251.

[27] Jenner, P. J.; Ellard, G. A.; Gruer, P. J.; Aber, V. R. A comparison of the blood levels and urinary excretion of ethionamide and prothionamide in man. J. Antimicrob. Chemother., 1984, 13, 267277.

[28] Quémard, A.; Laneelle, G.; Lacave, C. Mycolic acid synthesis: a target for ethionamide in mycobacteria? Antimicrob. Agents Chemother., 1992, 36, 1316-1321.

[29] Peloquin, C. A.; James, G. T.; McCarthy, E.; Goble, M. Pharmacokinetic evaluation of ethionamide suppositories. Pharmacotherapy, 1991, 11, 359-363.

[30] Auclair, B.; Nix, D. E.; Adam, R. D.; James, G. T.; Peloquin, C. A. Pharmacokinetics of ethionamide administered under fasting conditions or with orange juice, food, or antacids. Antimicrob. Agents Chemother., 2001, 45, 810-814.

[31] Zhu, M.; Namdar, R.; Stambaugh, J. J.; Starke, J. R.; Bulpitt, A. E.; Berning, S. E.; Peloquin, C. A. Population pharmacokinetics of ethionamide in patients with tuberculosis. Tuberculosis, 2002, 82, 91-96.

[32] Baulard, A. R.; Betts, J. C.; Engohang-Ndong, J.; Quan, S.; McAdam, R. A.; Brennan, P. J.; Locht, C.; Besra, G. S. Activation of the pro-drug ethionamide is regulated in mycobacteria. J. Biol. Chem., 2000, 275, 28326-28331.

[33] DeBarber, A. E.; Mdluli, K.; Bosman, M.; Bekker, L. G.; Barry, C. E., 3rd. Ethionamide activation and sensitivity in multidrugresistant Mycobacterium tuberculosis. Proc. Natl. Acad. Sci. U S A, 2000, 97, 9677-9682.

[34] Francois, A. A.; Nishida, C. R.; de Montellano, P. R.; Phillips, I. R.; Shephard, E. A. Human flavin-containing monooxygenase 2.1 catalyzes oxygenation of the antitubercular drugs thiacetazone and ethionamide. Drug Metab. Dispos., 2009, 37, 178-186.

[35] Nishida, C. R.; Ortiz de Montellano, P. R. Bioactivation of antituberculosis thioamide and thiourea prodrugs by bacterial and mammalian flavin monooxygenases. Chem. Biol. Interact., 2011, 192, 21-25.

[36] Qian, L.; Ortiz de Montellano, P. R. Oxidative activation of thiacetazone by the Mycobacterium tuberculosis flavin monooxygenase EtaA and human FMO1 and FMO3. Chem. Res. Toxicol., 2006, 19, 443-449.

[37] Wang, F.; Langley, R.; Gulten, G.; Dover, L. G.; Besra, G. S.; Jacobs, W. R., Jr.; Sacchettini, J. C. Mechanism of thioamide drug action against tuberculosis and leprosy. J. Exp. Med., 2007, 204, 73-78.

[38] Dover, L. G.; Alahari, A.; Gratraud, P.; Gomes, J. M.; Bhowruth, V.; Reynolds, R. C.; Besra, G. S.; Kremer, L. EthA, a common activator of thiocarbamide-containing drugs acting on different mycobacterial targets. Antimicrob. Agents Chemother., 2007, 51, 1055-1063.

[39] Phetsuksiri, B.; Jackson, M.; Scherman, H.; McNeil, M.; Besra, G. S.; Baulard, A. R.; Slayden, R. A.; DeBarber, A. E.; Barry, C. E., 3rd; Baird, M. S.; Crick, D. C.; Brennan, P. J. Unique mechanism of action of the thiourea drug isoxyl on Mycobacterium tuberculosis. J. Biol. Chem., 2003, 278, 53123-53130.

[40] Hanoulle, X.; Wieruszeski, J. M.; Rousselot-Pailley, P.; Landrieu, I.; Locht, C.; Lippens, G.; Baulard, A. R. Selective intracellular accumulation of the major metabolite issued from the activation of the prodrug ethionamide in mycobacteria. J. Antimicrob. Chemother., 2006, 58, 768-772.

[41] Hanoulle, X.; Wieruszeski, J. M.; Rousselot-Pailley, P.; Landrieu, I.; Baulard, A. R.; Lippens, G. Monitoring of the ethionamide prodrug activation in mycobacteria by (1) $\mathrm{H}$ high resolution magic angle spinning NMR. Biochem. Biophys. Res. Commun., 2005, 331, 452-458.

[42] Fraaije, M. W.; Kamerbeek, N. M.; Heidekamp, A. J.; Fortin, R.; Janssen, D. B. The prodrug activator EtaA from Mycobacterium tuberculosis is a Baeyer-Villiger monooxygenase. J. Biol. Chem., 2004, 279, 3354-3360.

[43] Stevens, G. J.; Hitchcock, K.; Wang, Y. K.; Coppola, G. M.; Versace, R. W.; Chin, J. A.; Shapiro, M.; Suwanrumpha, S.; Mangold, B. L. In vitro metabolism of N-(5-chloro-2methylphenyl)-N'-(2-methylpropyl)thiourea: species comparison and identification of a novel thiocarbamide-glutathione adduct. Chem. Res. Toxicol., 1997, 10, 733-741.

[44] Johnsson, K.; King, D. S.; Schultz, P. G. Studies on the mechanism of action of isoniazid and ethionamide in the chemotherapy of tuberculosis. J. Am. Chem. Soc. 1995, 117, 5009-5010.

[45] Morlock, G. P.; Metchock, B.; Sikes, D.; Crawford, J. T.; Cooksey, R. C. ethA, inhA, and katG loci of ethionamide-resistant clinical Mycobacterium tuberculosis isolates. Antimicrob. Agents Chemother., 2003, 47, 3799-3805.

[46] Vilchèze, C.; Weisbrod, T. R.; Chen, B.; Kremer, L.; Hazbon, M. H.; Wang, F.; Alland, D.; Sacchettini, J. C.; Jacobs, W. R., Jr. Altered NADH/NAD+ ratio mediates coresistance to isoniazid and ethionamide in mycobacteria. Antimicrob. Agents Chemother., 2005, 49, 708-720.

[47] Hou, B. K.; Ellis, L. B.; Wackett, L. P. Encoding microbial metabolic logic: predicting biodegradation. J. Ind. Microbiol. Biotechnol., 2004, 31, 261-272.

[48] Dodge, A. G.; Richman, J. E.; Johnson, G.; Wackett, L. P. Metabolism of thioamides by Ralstonia pickettii TA. Appl. Environ. Microbiol., 2006, 72, 7468-7476.

[49] Newton, G. L.; Bewley, C. A.; Dwyer, T. J.; Horn, R.; Aharonowitz, Y.; Cohen, G.; Davies, J.; Faulkner, D. J.; Fahey, R. C. The Structure of U17 Isolated from Streptomyces-Clavuligerus and Its Properties as an Antioxidant Thiol. Eur. J. Biochem., 1995, 230, 821-825.

[50] Sakuda, S.; Zhou, Z. Y.; Yamada, Y. Structure of a novel disulfide of 2-(N-acetylcysteinyl)amido-2-deoxy-alpha-D-glucopyranosylmyo-inositol produced by Streptomyces sp. Biosci. Biotechnol. Biochem., 1994, 58, 1347-1348.

[51] Newton, G. L.; Unson, M. D.; Anderberg, S. J.; Aguilera, J. A.; Oh, N. N.; delCardayre, S. B.; Av-Gay, Y.; Fahey, R. C. Characterization of Mycobacterium smegmatis mutants defective in 1-d-myo-inosityl-2-amino-2-deoxy-alpha-d-glucopyranoside and mycothiol biosynthesis. Biochem. Biophys. Res. Commun., 1999, 255, 239-244.

[52] Rawat, M.; Johnson, C.; Cadiz, V.; Av-Gay, Y. Comparative analysis of mutants in the mycothiol biosynthesis pathway in Mycobacterium smegmatis. Biochem. Biophys. Res. Commun., 2007, 363, 71-76.

[53] Rawat, M.; Kovacevic, S.; Billman-Jacobe, H.; Av-Gay, Y. Inactivation of $\mathrm{mshB}$, a key gene in the mycothiol biosynthesis pathway in Mycobacterium smegmatis. Microbiology, 2003, 149, 1341-1349.

[54] Newton, G. L.; Buchmeier, N.; Fahey, R. C. Biosynthesis and functions of mycothiol, the unique protective thiol of Actinobacteria. Microbiol. Mol. Biol. Rev., 2008, 72, 471-494.

[55] Vilchèze, C.; Av-Gay, Y.; Barnes, S. W.; Larsen, M. H.; Walker, J. R.; Glynne, R. J.; Jacobs, W. R., Jr. Coresistance to isoniazid and ethionamide maps to mycothiol biosynthetic genes in Mycobacterium bovis. Antimicrob. Agents Chemother., 2011, 55, $4422-4423$.

[56] Xu, X.; Vilchèze, C.; Av-Gay, Y.; Gomez-Velasco, A.; Jacobs, W. R., Jr. Precise null deletion mutations of the mycothiol synthesis genes reveal their role in isoniazid and ethionamide resistance in Mycobacterium smegmatis. Antimicrob. Agents Chemother., 2011, 55, 3133-3139.

[57] Ethionamide. Tuberculosis (Edinb), 2008, 88, 106-108.

[58] Weber, W.; Schoenmakers, R.; Keller, B.; Gitzinger, M.; Grau, T.; Daoud-El Baba, M.; Sander, P.; Fussenegger, M. A synthetic mammalian gene circuit reveals antituberculosis compounds. Proc. Natl. Acad. Sci. U S A, 2008, 105, 9994-9998.

[59] Willand, N.; Dirie, B.; Carette, X.; Bifani, P.; Singhal, A.; Desroses, M.; Leroux, F.; Willery, E.; Mathys, V.; Deprez-Poulain, R.; Delcroix, G.; Frenois, F.; Aumercier, M.; Locht, C.; Villeret, V.; Deprez, B.; Baulard, A. R. Synthetic EthR inhibitors boost antituberculous activity of ethionamide. Nat. Med., 2009, 15, 537 544.

[60] Smith, P. B.; Crespi, C. Thiourea toxicity in mouse C3H/10T1/2 cells expressing human flavin-dependent monooxygenase 3 . Biochem. Pharmacol., 2002, 63, 1941-1948. 
[61] Henderson, M. C.; Krueger, S. K.; Stevens, J. F.; Williams, D. E. Human flavin-containing monooxygenase form 2 S-oxygenation: sulfenic acid formation from thioureas and oxidation of glutathione. Chem. Res. Toxicol., 2004, 17, 633-640.

[62] Onderwater, R. C.; Commandeur, J. N.; Vermeulen, N. P. Comparative cytotoxicity of N-substituted N'-(4-imidazoleethyl)thiourea in precision-cut rat liver slices. Toxicology, 2004, 197, 81-91.

[63] Henderson, M. C.; Siddens, L. K.; Morre, J. T.; Krueger, S. K.; Williams, D. E. Metabolism of the anti-tuberculosis drug ethionamide by mouse and human FMO1, FMO2 and FMO3 and mouse and human lung microsomes. Toxicol. Appl. Pharmacol., 2008, 233, 420-427.

[64] Brossier, F.; Veziris, N.; Truffot-Pernot, C.; Jarlier, V.; Sougakoff, W. Molecular investigation of resistance to the antituberculous drug ethionamide in multidrug-resistant clinical isolates of Mycobacterium tuberculosis. Antimicrob. Agents Chemother., 2011, 55, 355-360.

[65] Carette, X.; Blondiaux, N.; Willery, E.; Hoos, S.; Lecat-Guillet, N.; Lens, Z.; Wohlkonig, A.; Wintjens, R.; Soror, S. H.; Frenois, F.; Dirie, B.; Villeret, V.; England, P.; Lippens, G.; Deprez, B.; Locht, C.; Willand, N.; Baulard, A. R. Structural activation of the transcriptional repressor EthR from Mycobacterium tuberculosis by single amino acid change mimicking natural and synthetic ligands. Nucleic Acids Res., 2011.

[66] Dover, L. G.; Corsino, P. E.; Daniels, I. R.; Cocklin, S. L.; Tatituri, V.; Besra, G. S.; Futterer, K. Crystal structure of the TetR/CamR family repressor Mycobacterium tuberculosis EthR implicated in ethionamide resistance. J. Mol. Biol., 2004, 340, 1095-1105.

[67] Frénois, F.; Engohang-Ndong, J.; Locht, C.; Baulard, A. R.; Villeret, V. Structure of EthR in a ligand bound conformation reveals therapeutic perspectives against tuberculosis. Mol. Cell, 2004, 16, 301-307.

[68] Frénois, F.; Baulard, A. R.; Villeret, V. Insights into mechanisms of induction and ligands recognition in the transcriptional repressor
EthR from Mycobacterium tuberculosis. Tuberculosis, 2006, 86, 110-114.

[69] Engohang-Ndong, J.; Baillat, D.; Aumercier, M.; Bellefontaine, F.; Besra, G. S.; Locht, C.; Baulard, A. R. EthR, a repressor of the TetR/CamR family implicated in ethionamide resistance in mycobacteria, octamerizes cooperatively on its operator. Mol. Microbiol., 2004, 51, 175-188.

[70] Katrahalli, U.; Kalalbandi, V. K.; Jaldappagari, S. The effect of anti-tubercular drug, ethionamide on the secondary structure of serum albumins: a biophysical study. J. Pharm. Biomed. Anal., 2012, 59, 102-108

[71] Allegretti, P. E.; Milazzo, C. B.; Castro, E. A.; Furlong, J. J. P. Mass spectrometry as a valuable tool for the study of tautomerism of amides and thioamides. J. Mol. Struc-Theochem., 2002, 589, $161-170$.

[72] Cardoso, S. H.; Vieira De Almeida, M.; Vitor De Assis, J.; Diniz R.; Speziali, N. L.; De Souza, M. V. N. Synthesis and characterization of n-hydroxyalkyl and oxazolinyl ethionamide derivatives. J. Sulfur Chem., 2008, 29, 145-149.

[73] Cynamon, M. H.; Sklaney, M. Gatifloxacin and ethionamide as the foundation for therapy of tuberculosis. Antimicrob. Agents Chemother., 2003, 47, 2442-2444.

[74] Wilson, M.; DeRisi, J.; Kristensen, H. H.; Imboden, P.; Rane, S Brown, P. O.; Schoolnik, G. K. Exploring drug-induced alterations in gene expression in Mycobacterium tuberculosis by microarray hybridization. Proc. Natl. Acad. Sci. U S A, 1999, 96, 1283312838.

[75] Banerjee, A.; Dubnau, E.; Quemard, A.; Balasubramanian, V.; Um, K. S.; Wilson, T.; Collins, D.; de Lisle, G.; Jacobs, W. R., Jr. InhA a gene encoding a target for isoniazid and ethionamide in Mycobacterium tuberculosis. Science, 1994, 263, 227-230.

[76] Chen, L. C.; Yeh, H. Y.; Yeh, C. Y; Arias, C. R.; Soo, V. W. Identifying co-targets to fight drug resistance based on a random walk model. BMC Syst. Biol., 2012, 6, 5 . 